\title{
Interactive comment on "Application of particle swarm optimization for gravity inversion of 2.5-D sedimentary basins using variable density contrast" by Kunal Kishore Singh and Upendra Kumar Singh
}

\section{Kunal Kishore Singh and Upendra Kumar Singh}

upendra.ism@gmail.com

Received and published: 19 January 2017

Dear Sir Thank for given suggestions by Prof. Dr. Gadirov, Referee for improving our manuscript. I have appended the correction in page 10, line 211-213. Apart from this, one reference two references are deleted from the reference list from page 9 have been deleted which were not mentioned in the text in earlier manuscript. Chakravarthi, V., 1994. Gravity interpretation of non-outcropping sedimentary basins in which the density contrast decreases parabolically with depth: Pure and Applied Geophysics, 145, 327-335. Chakravarthi, V.,Raghuram, H. M.,Singh, S. B.,2002. 3-D forward gravity

Printer-friendly version

Discussion paper 
modeling of basement interfaces above which the density contrast varies continuously with depth. Computer and Geosciences 28, 53-57.

If you have still some more suggestions needs for improvement of our manuscript, we would appreciate and welcome for inclusion.

with kind regard Upendra

Interactive

comment

Please also note the supplement to this comment:

http://www.geosci-instrum-method-data-syst-discuss.net/gi-2016-10/gi-2016-10-AC4supplement.pdf

Interactive comment on Geosci. Instrum. Method. Data Syst. Discuss., doi:10.5194/gi-201610, 2016. 